ORO, Ari Pedro; SIEll, Carlos Alberto (Org.). Globalização e religião. Petropolis: Vozes, 1997. $262 \mathrm{p}$.

\title{
Emerson Giumbelli*
}

\section{Universidade Federal do Rio de Janeiro, Museu Nacional - Brasil}

Em novembro de 1996, realizou-se em Porto Alegre a VI Jornada sobre Alternativas Religiosas na América Latina, congresso que reuniu mais de uma centena de estudiosos do Brasil, Argentina, Uruguai e Chile. Sua organização envolveu o Programa de Pós-Graduação em Antropologia Social da UFRGS, através do NER (Núcleo de Estudos da Religião), e a Associação de Cientistas Sociais da Religião do Mercosul, cujo objetivo é exatamente traduzir em um plano mais durável os contatos e os diálogos que tiveram lugar durante o evento. Este livro, cujo título reproduz o tema do congresso - "Globalização e Religião”-, publica suas três conferências e os dez trabalhos apresentados em duas mesas-redondas, precedidos por uma sintética introdução por parte dos organizadores do volume.

“Globalização" é certamente um tema que vem ganhando atenção destacada nas problematizações recentes sobre o lugar da religião nas sociedades (vide os textos de autores tais como Roland Robertson, Peter Beyer e Samuel Huntington), repondo e retomando questões clássicas do estudo dos fenômenos religiosos (secularização, institucionalização) e originando outras novas (nacionalismos e fundamentalismos religiosos). Sua discussão faz-se, assim, mais do que necessária. Entretanto, no caso do congresso, a escolha do tema teve um efeito interessante, pois serviu para marcar e caracterizar o fato de que se reuniam estudiosos de diferentes países da América do Sul - numa rara e privilegiada situação que as mesas-redondas procuraram explorar. O livro, portanto, compila um conjunto de reflexões em tomo da categoria "globalização” (concentradas nos três primeiros capítulos, mas não ausentes em vários dos demais) e uma série de abordagens das situações religiosas de Brasil,

* Doutorando em Antropologia Social. 
Argentina, Uruguai e Chile, bem como de algumas relações e fluxos existentes entre elas. A relevância e a oportunidade do tema geral, a originalidade dos enfoques e o ineditismo da reunião dos autores, tudo se soma para conferir relevância ao livro.

A primeira parte do livro inicia-se com o texto do único não sul-americano, o sociólogo italiano Enzo Pace. Depois de enfatizar a complexidade e as divergências do debate atual sobre globalização, Pace sugere dois pontos para caracterizá-la: a tendência ao desenraizamento, atingindo a todos os grupos através de processos muito concretos como a as migrações em massa e a produção transnacionalizada e circulação irrestrita das mercadorias. Para as religiões, a consequência seria o comprometimento de sua capacidade de reprodução enquanto fonte de imagens estáveis do mundo, o que atingiria sobretudo as grandes instituições. Em tal situação, estas acelerariam sua adaptação ao mundo moderno, utilizando-se de seus recursos e recorrendo, mesmo no diálogo inter-religioso, aos temas da agenda mundial. A contrapartida disso estaria na subjetivação dos sistemas de crença, dado que o lugar da construção do sentido tenderia a se deslocar para a livre iniciativa individual, produzindo e se alimentando de uma nova religião mundial mais compatível com "tradições inventadas".

As divisões entre o caráter da globalização e suas consequências para a religião, nítidas no argumento de Pace, desaparecem no texto seguinte de Otávio Velho. Seu esforço vai na direção de apontar processos que atravessam, ao mesmo tempo, na Antropologia, a religião e a própria realidade mundial, configurando uma espécie de "espírito de época”. Isso exige uma série de transmutações no conceito de globalização, que se constitui sucessivamente como: objeto, desde que se não o tome de modo essencialista e oposto à localização; perspectiva, o que levaria a privilegiar, em qualquer situação, os processos de interdependência; horizonte, na medida em que se o reconheça como referência necessária de discursos e práticas contemporâneos. Para o autor, as religiões, e especialmente as que mais crescem hoje no mundo, seriam portadoras de uma linguagem que traduz o tal "espírito de época”, marcado pela destradicionalização-reflexividade e pela desreificação-dissolução das oposições, e evidenciada pela circulação generalizada dos mesmos significantes. Isso traria desafios sérios para a Antropologia e se somaria aos questionamentos que partem do interior da própria disciplina, uns e outros centrados na categoria, a um só tempo generalizada e contestada, "cultura”. Como saída, Velho sugere uma alternativa ao universalismo transcendente e às diferenças 
reificadas: um discurso das semelhanças e das aproximações contingentes, impulsionando para atitudes de diplomacia e civilidade.

Reginaldo Prandi retoma a idéia de modernidade como desencantamento e nesse eixo dispõe os efeitos da globalização sobre a religião. Assim, o que caracteriza a situação atual da religião a partir do Ocidente não é o crescimento de sua influência para orientar indivíduos e sociedades, mas sua transformação em serviço, ou seja, sua adequação à lógica do mercado capitalista, o que se evidencia pelas suas regras de expansão e meios de difusão. Se os diversos sistemas religiosos (e não somente as chamadas religiões mundiais) se autonomizam em relação a territórios localizados, ganhando poderes inéditos de disseminação, isso se produz como contrapartida de uma especialização. Especialização não no sentido de restrição de funções - ao contrário, como explicita Antonio Flavio Pierucci no texto que fecha o volume, ocorre uma flexibilização do conceito de atividade de atividade e uma borradura nos limites do campo religioso -, mas na medida em que as religiões passam a atender as demandas específicas de adeptos transmutados em consumidores de bens simbólicos, alimentando o pluralismo das alternativas.

As três contribuições, em sua competência e riqueza, suscitam várias reflexões. Chamam a atenção, em primeiro lugar, algumas convergências construídas mesmo em meio à diversidade dos enfoques. Assim, nenhum dos autores se contenta em tratar a globalização como mero objeto, preferindo problematizá-la enquanto cenário ou linhas de força, sendo que Velho e Pace acentuam seu caráter de perspectiva, e não apenas para os cientistas sociais, na medida em que se tomou categoria de vários discursos sociais. Também nenhum dos autores cai na armadilha de confundir globalização com homogeneização, apontando para a produção de diversidade e de pluralismo exatamente via a circulação mais intensa e ampliada de objetos, pessoas e sistemas simbólicos. Um ponto comum é a ênfase sobre a crise das instituições religiosas. Outros aspectos mereceram menos atenção, como a persistência de hegemonias e diferenças de poder em mundo globalizado (lembrada no livro por Rita Segato) e o fato das religiões enquanto forças elas mesmas, e talvez uma das primeiras, de globalização.

Além disso, a relação entre globalização e modernidade revela-se muitas vezes central e em tomo dela forma-se uma tensão entre antigos e velhos caminhos no estudo da religião. Ponto fundamental nessa discussão é a observação de que muito raramente se vê afirmar que as transformações ocorridas com 
a globalização equivalem ou superam aquelas produzidas com a entrada na “modernidade”. Enfim, muitos relutam em propor que estamos vivendo uma nova época e os que o assumem são comumente questionados pelos indicadores a que recorrem. Não espanta, então, que tanto Pace quanto Prandi apontem o reforço da secularização (tipicamente moderna) como consequência da globalização. Prandi vai mais longe: "não dispomos de uma boa nova teoria sobre o lugar da religião nessa sociedade de que falam as idéias sobre globalização e pós-modernidade” (p. 63). E Pierucci parece afirmar que essa teoria nem seria necessária: “a secularização é irrefreável e irreversível” (p. 259). O quadro torna-se menos previsível, porém, se privilegiamos um outro foco, o das sugestões metodológicas. Velho aponta desafios para a Antropologia e Pace propõe que demos maior atenção aos sincretismos, à perspectiva comparativa e ao papel das religiões como sistemas de comunicação que criam e relacionam o global e o local. E possível, como ocorre em outras épocas e campos de estudo, que desses investimentos metodológicos surjam alternativas teóricas (ou se visibilizem as já existentes), estabelecendo eixos interpretativos paralelos ou concorrentes ao da secularização.

A segunda parte do livro reúne os textos dedicados a tratar da situação religiosa em quatro países do Cone-Sul. Fortunato Mallimaci encarrega-se da Argentina, propondo um mapa religioso urbano constituído por três vetores. Haveria um campo instituído, dividido entre católicos, evangélicos e grupos minoritários; um conjunto de condutas e elaborações que configura uma religião difusa; e a atribuição de características sagradas a uma série de áreas seculares. A leitura, portanto, faz-se basicamente em torno da oposição institucionalizado/não institucionalizado, revelando uma realidade ainda bastante marcada pela hegemonia católica e pelos desafios que lhe surgem de interior como de seu exterior. Néstor da Costa na sua análise do Uruguai privilegia outro eixo, o da variação diacrônica na intensidade da presença da religião na sociedade. Assim, o momento atual marcaria a transição de uma época em que o religioso se restringia à esfera do privado (dada a debilidade católica e o sucesso da política oficial secularizadora), para outra caracterizada por ambiente social favorável ao religioso e a sua ocupação de espaços públicos. Pierre Sanchis propõe uma leitura do campo religioso brasileiro a partir da coexistência e articulação de "três modernidades": a pré-modernidade, traduzida no sincretismo a partir de diferentes matrizes (primeiro, católica e africana, acrescidas depois da espírita); a modernidade, como tendência 
dessincretizante, presente especialmente, mas não só, entre os evangélicos; a pós-modernidade, que consagra um ecletismo a partir dos desejos e trajetórias de um self, como articuladora de novas vertentes do campo religioso (Nova Era) e força a penetrar as já existentes. O acento dessa leitura recai sobre a idéia de pluralidade, sempre presente e agora recriada na dinâmica e na lógica do campo religioso brasileiro - ainda que, como nota Pierucci, nossa diversidade esteja quase que restrita às vertentes cristãs. Já no Chile, segundo Cristian Parker, o pluralismo seria uma novidade marcante e é esse o aspecto enfatizado em seu inventário institucional do campo religioso. Outra preocupação do autor reside em avaliar o grau de racionalização da visão de mundo, constatando que tal racionalização ocorre de par com a permanência de um núcleo sólido de crenças mágico-religiosas tipicamente populares e com a introdução de crenças new age.

O panorama a que se chega com os quatro textos, além de propiciar o diálogo entre as várias "sociologias nacionais" e fazer circular dados e perspectivas, permite perceber processos comuns, pelo menos em seus resultados e consequências, às várias situações. Um ponto evidente são os desafios que atingem ao catolicismo, em sua herança de religião dos colonizadores, seja de seu interior (novos movimentos, distanciamento dos fiéis), seja do seu exterior, pois a pluralização do campo religioso vem se tornando irreversível em todos os países. O pluralismo é reforçado por outro processo, de desinstitucionalização da religião, aumentando o contingente de pessoas que vivem como crentes "sem religião" ou "sem igreja” — embora, como nota Mallimaci, esta tendência seja contrabalançada por movimentos de institucionalização, visíveis especialmente na ligação da população mais pobre com as igrejas pentecostais. Em seu rápido comentário destes textos, Abelardo Jorge Soneira destaca esses pontos, acrescentando uma nota sobre a "vitalidade das expressões religiosas em nossos países e o papel que jogam em uma modernidade em crise em direção ao fim do milênio” (p. 149). Com efeito, é preciso dar conta de situações que se assemelham ao apresentar, ao mesmo tempo, "menos" e “mais” religião. Por um lado, tende a se desfazer nesses países o monopólio do catolicismo e sua relação privilegiada com Estado, e a aumentar o pluralismo e o trânsito religiosos, tudo isso nos aproximando de um modelo moderno do religioso. Por outro lado, há “mais” religião nas cidades, nos meios de comunicação e na política partidária e é evidente que a "religião” está hoje na agenda pública de todos esses países muito mais do que estava duas décadas atrás. 
Há, também, muito “mais religião” ultrapassando fronteiras, na medida em que às estruturas transnacionais das grandes religiões se acrescentam o trânsito de sistemas simbólicos e personagens vinculados a grupos minoritários e menos estruturados. Este é o tema da última parte do livro e as análises proporcionadas pelos quatro textos que se detêm sobre o fenômeno não apenas complementam ou se justapõem às apresentações anteriores das situações religiosas, mas as enriquecem e matizam. Alejandro Frigerio resume suas interpretações sobre a recepção das religiões afro-brasileiras na Argentina, partindo de uma teoria sobre as condições e estratégias de tradução de sistemas simbólicos na passagem de um contexto social para outro. Essas traduções ocorrem tanto no nível do recrutamento e conversão, para o qual importam as semelhanças entre as religiões afro-brasileiras e o catolicismo popular argentino, quanto no nível da reação dos umbandistas/africanistas às acusações que partem da sociedade, apelando primeiro para uma conformação ao modelo católico de definição do religioso e depois para um argumento cultural de pertencimento à tradição africana. Ari Pedro Oro explora também a expansão das religiões afro-brasileiras para além das fronteiras nacionais, mas acompanhando a atuação nos anos 70 de dois personagens ligados a uma federação de umbanda gaúcha. O primeiro caso, que se passa entre Porto Alegre e Montevideo, retoma o papel das federações na legitimação social dos cultos afro-brasileiros; o outro documenta mais um episódio de vinculação entre as atividades de pais-de-santo e projetos políticos (envolvendo desta vez o principal assessor de Perón), em trânsitos aproximando cidades brasileiras e argentinas. No texto de Renzo Pi Hugarte, o aspecto central é a oposição entre duas formas de pluralização do campo religioso no Uruguai. Por muito tempo, a introdução de religiões não-católicas ocorreu associada à migração de grupos étnicos e que pouco atingiram a configuração total do campo religioso; já a chegada dos cultos de possessão e dos neopentecostais, vindos do Brasil, seguiu outra dinâmica, mais "missionária”, e gerou mudanças e reações mais acentuadas, dentro e fora do campo religioso.

A intervenção de Rita Segato obedece a um perfil bem distinto. Não privilegia casos empíricos e toma a direção de uma perspectiva ampla de análise que subordina a globalização à importância da nação como estrutura e matriz de diversidade. $\mathrm{O}$ estatuto da nação define-se na interseção de duas situações, dadas, uma, pela hierarquia que produz e relaciona doadores e receptores de modernidade, e outra, pela composição entre etnias e segmentos 
que constituem e ao mesmo tempo ameaçam a totalidade nacional. Essa composição organiza-se ao modo de matrizes de diversidade, ilustrada pela autora pelas diferenças entre Argentina (homogeneização e supressão das minorias), Estados Unidos (pluralismo a partir de identidades essencialistas, gerador de segregações) e Brasil (pluralismo inclusivo e que se reproduz pela interpenetração das identidades). Com base nisso, afirma que "é possível entender toda opção religiosa com referência à nação e no contexto dos outros grupos que convivem nela” (p. 232). Ou seja, os posicionamentos religiosos assumem significados não só religiosos (políticos, étnicos) e, em se tratando da adesão a novas crenças, esta se faz em um cenário necessariamente distinto daquele a que remetem originalmente.

As opções e ênfases de Segato colocam em jogo uma tensão quase sempre lembrada nas discussões sobre globalização, e também reproduzida na introdução ao livro, na qual se procura articular a transposição de fronteiras com a especificidade de cada país na recepção de formas religiosas. Efetivamente, muitas das reações ao trânsito de religiões entre esses países assumem marcos que remetem a trajetórias e debates nacionais. Um exemplo são as controvérsias sociais em torno da legitimidade dos cultos afros, pentecostais e outros novos grupos (muitas vezes considerados “seitas”), às quais vários textos do livro fazem referência, e que envolvem privilegiadamente o Estado e as questões nacionais. Um dos efeitos dessas controvérsias consiste no redimensionamento das classificações utilizadas, pelos mais diferentes atores sociais, para mapear o campo religioso, e é pena que nenhum dos autores tenha trabalhado esse problema. Além disso, em muitos casos, pode-se perguntar se o principal significado da transnacionalização de religiões está na transposição de fronteiras ou no reforço delas - ou seja, em que medida esses movimentos não contribuem para recolocar, aceitando-as, identidades nacionais ou regionais? É curioso que ninguém tenha notado a unidirecionalidade dos fluxos religiosos mais destacados: são quase sempre brasileiros os pentecostalismos e cultos de possessão que chegam até Uruguai e Argentina e as migrações de missionários e aprendizes seguem claramente esse eixo, elevando o português a espécie de língua sagrada. Como nesse processo se constróem imagens do Brasil e dos brasileiros e do próprio Cone-Sul enquanto região? Por que o Chile parece estar excluído desse sistema de trocas? Talvez essas sejam perguntas mais produtivas e mais adequadas diante da situação concreta em nossos países e que só são formuláveis quando substituímos por marcos mais restritos o cenário 
da globalização - o que não requer abandoná-lo, mas tomá-lo no sentido proposto por Velho, enquanto horizonte de questões.

Uma dimensão que pouco ou nada aparece nos textos já comentados é a avaliação da produção científica sobre religião no Cone-Sul, bem como de seus produtores. As colocações de Antonio Flávio Pierucci contribuem para cobrir essa lacuna, ainda que de forma parcial e específica. Pierucci explicita sua preocupação com os resultados do trabalho de intelectuais que se dedicam aos fenômenos religiosos e, ao mesmo tempo, estão situados no interior do campo religioso. Para ele, as duas coisas se relacionam pelo crescimento da "boa vontade cultural” para com a religião, que enfatizaria apenas seus aspectos positivos para a vida social. Seria necessário então que tais intelectuais realizassem um esforço de sociologização do próprio trabalho, evitando que posições religiosas acabem legitimadas por metodologias (aparentemente) científicas. Esta não é, a rigor, uma questão nova (no Brasil, e não só aqui, o catolicismo começou a ser estudado cientificamente por religiosos), o que não a torna menos atual ou pertinente. Além disso, é preciso lembrar que ela deriva tanto das virtualidades da situação de religiosos sociólogos, quanto da posição que não vê outra alternativa ao elogio da religião senão sua crítica: “a sociologia da religião só é possível porque tem na crítica moderna da religião sua condição pós-tradicional de possibilidade enquanto ciência” (p. 257).

Qual então a novidade nas condições de produção da sociologia da religião? Pierucci tem razão ao apontar para a flexibilização e a imprecisão dos limites do campo religioso, dando como exemplo episódios das controvérsias sociais mencionadas acima. Mas se isto está correto, então a exigência de reflexividade sobre o próprio trabalho não poderia se restringir aos sociólogos religiosos. Numa situação em que mesmo os personagens e instituições mais seculares podem estar envolvidos na definição de identidades e legitimidades religiosas, os cientistas sociais, religiosos ou não, estão necessariamente posicionados e são muitas vezes explicitamente chamados a participar do processo. Daí o significado deste livro, que além de ter todas as condições para se tornar uma referência entre as abordagens sociológicas/antropológicas dos fenômenos religiosos nos e entre os países considerados, representa a intervenção de intelectuais na abordagem de questões que preocupam a sociedade como um todo. 